\title{
Effectiveness of Arbuscular Mycorrhizal Fungi based biofertilizer on early growth of coconut seedlings
}

\author{
I.M.P.S. Ilangamudali ${ }^{1^{*}}$ and S.H.S. Senarathne ${ }^{1}$ \\ ${ }^{1}$ Agronomy Division, Coconut Research Institute, Lunuwila, 61150, Sri Lanka \\ *Corresponding Author: I.M.P.S. Ilangamudali, E mail: sachithya@gmail.com
}

\begin{abstract}
Coconut (Cocos nucifera $\mathrm{L}$ ) is one of the predominant plantation crops in Sri Lanka. The success of a coconut plantation, in terms of its establishment as well as its future performance, is heavily dependent on the quality of the seedling used. Thus attention needs to pay to raise healthy seedlings in coconut nurseries.
\end{abstract}

Coconut nurseries adopt different agronomic practices to produce good quality seedlings. In this process, applying mycorrhizal inoculants is becoming an increasingly common practice in plant nurseries. Therefore the effects of mycorrhizae based biofertilizer on root and shoot development of coconut seedlings was evaluated under nursery conditions for a period of seven months. The treatments were the presence of mycorrhizae based biofertilizer (T1) and absence of mycorrhizae based biofertilizer (T2). Application of mycorrhizae based biofertilizer had no significant effect on growth parameters tested in the early stages of seedling development up to four months. In contrast, the bio fertilizer significantly increased the numbers, volumes and dry weights of primary, secondary, tertiary and quaternary roots and stem girth at the latter stages of seedling growth. The leaf area and seedling height were not significantly increased by application of biofertilizer during the nursery period. These results revealed that the usage of mycorrhizae based biofertilizer positively affected root development and stem girth of coconut seedlings. The application of the mycorrhizae based biofertilizer seems to be beneficial to produce high quality seedlings with welldeveloped roots and thus obtain good field establishment, thereby reducing the number casualties at early field establishment.

Key words: Bio fertilizer, coconut nursery, mycorrhizae, roots and shoots

\section{INTRODUCTION}

Coconut (Cocos nucifera) is one of the most important plantation crops in Sri Lanka. The cultivated extent of coconut in Sri Lanka is about 395,000 ha with an annual production of 2940 million nuts (Central Bank Report,
2012). Generally, maintenance of senile coconut plantations with handling of improper genetic materials has largely contributed to low productivity of coconut plantations. One of the main reasons for this high motility rate of seedling is low vigour, especially less developed root and shoots system (Senarathne et al., 2012). 
Under this condition, rehabilitation of coconut plantations with quality seedlings needs to be promoted and to maintain a proper coconut plantation, high quality coconut seedlings must be used as it helps to establish a healthy and uniform plantation. This is a critical point of coconut cultivation. Thus, nursery management techniques play an important role in coconut cultivation in producing high quality planting materials that will ultimately provide higher yields (Menon and Pandalai, 1958). Standardized nursery techniques help in producing large quantities of quality seedlings at relatively low costs (Menon and Pandalai, 1958). Among the cultural practices in coconut nurseries, irrigation, manuring and weeding are considered to be crucial. During the nursery period, inorganic fertilizers are applied to increase the seedling growth and to overcome nutrient deficiencies. However, applying mycorrhizal inoculants is becoming an increasingly common practice in plant nurseries. Whether nurseries are producing native, ornamental, or agricultural plants, adding mycorrhizae can lower mortality rates of plants and reduce water and plant nutrient consumption (Coyne and Mark, 1999). There are many ways that mycorrhizae facilitate healthy plant growth and finally help to produce quality seedlings in the nursery (Linderman and Davis, 2004).

Mycorrhizal technology plays vital role in sustaining plant-soil ecosystems (Jeffries and Barea, 2000; Gianinazzi et al., 2002). Mycorrhizae can increase the surface area of a plant root system (Miller and Jastrow, 1992) as a result; the plant is able to absorb more water and nutrients. This increase in water uptake helps the survival of transplants and facilitates drought resistance. In most cases, mycorrhizae benefit their host plants by improving nutrient uptake like phosphorus $(\mathrm{P})$, nitrogen $(\mathrm{N})$, and micronutrients (Barea et al., 1991; Clark and
Zeto, 2000; Ward et al., 2001; Javaid, 2007). AM fungi also provide their host plants with protection against environmental abiotic stresses (Auge, 2001; Javad, 2007) as well as, biotic stress (Khaosaad et al., 2007). In addition, mycorrhizae enhance nitrogen fixation in nodule-forming plants (Kemery and Dana, 1995). Plants that receive proper nutrition are able to resist diseases, and this is one way that suppresses soil borne diseases (Linderman and Davis, 2004). The most obvious mechanism for protection against diseases is the barrier that Ectomycorrhizae create when they coat the external surface of the root (Castellano and Molina, 1989). Mycorrhizae compete with pathogenic microorganisms and may actually exude toxins and antibiotics to protect the plants and also root feeding nematodes are less likely to attack mycorrhizal plants (Khaosaad et al., 2007). Other benefits include improved soil structure due to the mycorrhizae binding soil particles into aggregates - allowing water to infiltrate and increasing oxygen in the rhizosphere (Coyne and Mark, 1999). Incorporation of biofertilizers which contain Arbuscular Mycorrhizal fungi (AMF) during the nursery period without incurring costs in supplying inorganic fertilizers can be an effective way of enhancing shoot and root growth (Marx et al., 1989). However no research had been carried out on AMF base bio fertilizers to understand its activity on root and shoot growth in coconut seedlings in Sri Lanka. This study was carried out to determine the impact of an AMF containing biofertilizer on seedling growth in coconut.

\section{MATERIALS AND METHODS}

This experiment was carried out at the Bandirippuwa Estate of the Coconut Research Institute of Sri Lanka which is located in the Intermediate Zone Low Country (IL1a) from 
November 2012 to July 2013. The mean annual rainfall was $1660 \mathrm{~mm}$ with fluctuation during dry periods. During the experimental period, the ambient air and soil temperature ranges between $280 \mathrm{C}$ to $320 \mathrm{C}$ and bright sunshine hours vary from 6 to 8 hours per day. The site was located in a well-drained flat land area without shade.

In this experiment, the biofertilizer was tested. It is produced by MALAYSIAN AGRI CARE SND. BHD. Company in Malaysia. Commercial name was; MYCOgold. It contains mycirrhizal hypae, infected root bits and viable spores with sterilized sand as the carrier medium. It contains $95 \%$ of endo-mycorrhizal spores and $5 \%$ of additives that assist in prolonging the shelf life of mycorrhiza. These additives also assist in improving the efficiency of biofertilizer in the field. It contain four genuses of endomycorrhizal spores, such as Acaulospora, Gigaspora, Glomus and Scutellospora. Also it contains sterilized sand and vermiculite.

Poly bags of $75 \mathrm{~cm}$ in height and $45 \mathrm{~cm}$ in width made of 500 gauges black polythene with gussets were used. Few punch holes were pierced on all sides close to the bottom to drain the excess water. The nursery stage poly bagged coconut seedlings were used in this study. The poly bags were filled with a potting mixture made up of coir dust and soil in a ratio of 3:1. High ratio of coir dust facilitates the uprooting of coconut seedlings without root damage. Coconut seedlings ( 2 months aged, tall $\mathrm{x}$ tall variety) were planted in individual poly bags and arranged at a spacing of $60 \mathrm{~cm} \mathrm{x} 60 \mathrm{~cm}$ in two separate plots according to the treatments. The experimental design was a Complete Randomized Design with five replicates.

$$
\text { Root volume }(\mathrm{ml})=\begin{aligned}
& \text { Displaced water volume }(\mathrm{ml}) \\
& \text { by known volume and roots }
\end{aligned}-\text { Known volume }(\mathrm{ml})
$$

The experiment consisted of two bio fertilizer treatments with Arbuscular Mycorrhizal Fungi (AMF) based biofertilizer (T1) and without Arbuscular Mycorrhizal Fungi (AMF) based biofertilizer (T2). Fifty gram (50 g) of AMF bio fertilizer was mixed well with the potting media in the poly bags at the time of planting seed nuts. All seedlings were managed by following the recommended nursery practices. The seedlings were maintained at near field capacity by watering at 3 day intervals in the absence of rainfall. Weed and pest control was done manually as per the recommendation of CRISL.

\section{Sampling and sample preparation}

Destructive samples were taken at four weekly intervals. At each sampling, four coconut seedlings were uprooted randomly from each treatment. First, seedling girth and seedling height were measured. Thereafter, the poly bag was removed and the potting mixture was washed away without damaging the roots, using running water. The coconut husk of the seed nut was carefully removed using a sharp knife. All the roots within the husk were removed and separated in to primary, secondary, tertiary and quaternary roots.

\section{Root measurements}

The root volume (ml) was taken by using the Archimedes principle (Burdette, 1979). A specific measuring cylinder was used to measure the displaced water volume. The separated root samples; primary, secondary, tertiary and quaternary roots, were immersed in a known volume of water in order to measure the displaced water volume.

Separated root samples were oven dried in 
separately at $800 \mathrm{C}$ to a constant weight. Dry weights $(\mathrm{g})$ of the different categories of roots were recorded.

\section{Shoot measurements}

Seedling girth and height $(\mathrm{cm})$ were measured using a measuring tape. The distance between shoot development point from the nut and the tip of the longest leaf was taken as the seedling height. To measure the leaf area, leaves were separated from the petiole and cut into pieces and leaf area was measured with an Automatic Leaf Area meter (USA LI COR 3100 ). Then the leaf petiole pieces were oven dried at $800 \mathrm{C}$ temperature to a constant weight and total shoot dry weight was determined.

\section{Data analysis}

Data was analyzed using an Analysis of Variance (ANOVA) procedure and means were separated using the Least Significant Difference (LSD).

\section{RESULTS}

\section{Effect of different treatments on root growth (volume) of coconut seedlings}

The volume of primary roots was not significant $(\mathrm{P}<0.05)$ between two treatments during the first three months (Table 1). From the third month onwards, seedlings treated with the AMF inoculum had larger primary roots, as depicted by the volume, when compared to the untreated plants. The differences were significant from up to the seventh month. The secondary root volume of plants grown with and without mycorrhizal inoculation were not significantly different $(\mathrm{P}<0.05)$ during first four months (Table 2). After fourth month, plants with inoculation (T1) had a significantly higher root volume when compared to non-inoculated plants until the eighth month. Furthermore, seedlings treated with the inoculum had comparatively higher root volumes at all samplings from fifth to eighth months.

\section{Table 1: Effect of biofertilizer on primary root volume $(\mathrm{ml})$ of coconut seedlings}

\begin{tabular}{lcccccccc}
\hline Treatments & \multicolumn{7}{c}{ Time (after treatment application) } \\
\hline & $1^{\text {st }}$ & $2^{\text {nd }}$ & $3^{\text {rd }}$ & $4^{\text {th }}$ & $5^{\text {th }}$ & $6^{\text {th }}$ & $7^{\text {th }}$ & $8^{\text {th }}$ \\
& Month & Month & Month & Month & Month & Month & Month & Month \\
\cline { 2 - 9 } T1 & 17.5 & 27.5 & 52.5 & 61.25 & 82.25 & 102.25 & 122.90 & 146.75 \\
T2 & 14.1 & 22.2 & 37.5 & 50.95 & 59.10 & 65.75 & 101.25 & 117.75 \\
Significance & ns & ns & ns & $*$ & $*$ & $*$ & $*$ & ns \\
LSD & - & - & - & 6.07 & 9.75 & 13.7 & 18.93 & \\
\hline
\end{tabular}

*Denote the significant difference at $p<0.05$; ns denote the non-significance

Table 2: Effect of biofertilizer on secondary root volume $(\mathrm{ml})$ of coconut seedlings

\begin{tabular}{lcccccccc}
\hline Treatments & \multicolumn{7}{c}{ Time (after treatment application) } \\
\hline & $1^{\text {st }}$ & $2^{\text {nd }}$ & $3^{\text {rd }}$ & $4^{\text {th }}$ & $5^{\text {th }}$ & $6^{\text {th }}$ & $7^{\text {th }}$ & $8^{\text {th }}$ \\
T1 & Month & Month & Month & Month & Month & Month & Month & Month \\
\cline { 2 - 9 } T2 & 3.85 & 4.75 & 28.00 & 32.37 & 39.1 & 59.25 & 67.25 & 93.10 \\
Significance & 2.02 & 2.65 & 11.40 & 18.50 & 23.2 & 33.25 & 39.75 & 53.25 \\
LSD & ns & ns & ns & ns & $*$ & $*$ & $*$ & $*$ \\
\hline
\end{tabular}

*Denote the significant difference at $p<0.05$; ns denote the non-significance 
Tertiary root volumes of the inoculated and non-inoculated plants were not significantly different $(\mathrm{P}<0.05)$ during the second and third month (there were no tertiary roots at the first sampling) (Table 3). From the third month onwards, plants in T1 had significantly higher root volumes when compared to those of T2. In general, seedlings treated with inoculum had comparatively higher root volumes when compared to non-treated seedlings at the time of field planting.

Table 3: Effect of biofertilizer on tertiary root volume $(\mathrm{ml})$ of coconut seedlings

\begin{tabular}{lcccccccc}
\hline Treatments & \multicolumn{7}{c}{ Time (after treatment application) } \\
\hline & $1^{\text {st }}$ & $2^{\text {nd }}$ & $3^{\text {rd }}$ & $4^{\text {th }}$ & $5^{\text {th }}$ & $6^{\text {th }}$ & $7^{\text {th }}$ & $8^{\text {th }}$ \\
T1 & Month & Month & Month & Month & Month & Month & Month & Month \\
\cline { 2 - 8 } T2 & 0 & 0.35 & 5.00 & 7.37 & 28.75 & 40.25 & 40.25 & 44.25 \\
Significance & 0 & 0.00 & 1.75 & 3.10 & 6.50 & 20.50 & 19.25 & 27.50 \\
LSD & ns & ns & ns & $*$ & $*$ & $*$ & $*$ & $*$ \\
& - & - & - & 2.54 & 8.45 & 9.22 & 13.18 & 9.58 \\
\hline
\end{tabular}

*Denote the significant difference at $p<0.05$; ns denote the non-significance

No quaternary roots were observed during the first two samplings. After the fifth month, inoculated seedlings had significantly higher quaternary root volumes (Table 4). However, seedlings treated with the inoculum had comparatively higher quaternary root volumes than the non-treated seedlings.

Table 4: Effect of biofertilizer on quaternary root volume $(\mathrm{ml})$ of coconut seedlings

\begin{tabular}{lcccccccc}
\hline Treatments & \multicolumn{7}{c}{ Time (after treatment application) } \\
\hline & $1^{\text {st }}$ & $2^{\text {nd }}$ & $3^{\text {rd }}$ & $4^{\text {th }}$ & $5^{\text {th }}$ & $6^{\text {th }}$ & $7^{\text {th }}$ & $8^{\text {th }}$ \\
T1 & Month & Month & Month & Month & Month & Month & Month & Month \\
\cline { 2 - 9 } T2 & 0 & 0 & 1.05 & 9.75 & 15.10 & 26.25 & 28.20 & 30.10 \\
Significance & 0 & 0 & 0.02 & 3.50 & 7.50 & 14.50 & 15.25 & 16.50 \\
LSD & ns & ns & ns & $*$ & ns & $*$ & $*$ & $*$ \\
\hline
\end{tabular}

*Denote the significant difference at $p<0.05$; ns denote the non-significance

The total root volumes of seedlings grown with and without mycorrhizal inoculation was not significantly different $(\mathrm{P}<0.05)$ during first three months (Table 5). From the fourth month onwards, seedlings with the inoculum had a significantly higher total root volume.

Table 5: Effect of biofertilizer on total root volume $(\mathrm{ml})$ of coconut seedlings

\begin{tabular}{lcccccccc}
\hline Treatments & \multicolumn{7}{c}{ Time (after treatment application) } \\
\hline & $1^{\text {st }}$ & $2^{\text {nd }}$ & $3^{\text {rd }}$ & $4^{\text {th }}$ & $5^{\text {th }}$ & $6^{\text {th }}$ & $7^{\text {th }}$ & $8^{\text {th }}$ \\
T1 & Month & Month & Month & Month & Month & Month & Month & Month \\
\cline { 2 - 9 } T2 & 21.35 & 32.60 & 86.55 & 110.75 & 165.0 & 228.00 & 258.60 & 314.20 \\
Significance & 16.02 & 24.90 & 50.67 & 75.42 & 96.25 & 134.00 & 175.50 & 215.10 \\
LSD & ns & ns & ns & ns & $*$ & $*$ & $*$ & $*$ \\
& - & - & - & - & 18.8 & 8.31 & 20.65 & 69.61 \\
\hline
\end{tabular}

$*$ Denote the significant difference at $p<0.05$; ns denote the non-significance 


\section{Effect of different treatments on root growth (dry weight) of coconut seedlings}

Dry weight of primary roots of inoculated and non-inoculated seedlings were not significantly different $(\mathrm{P}<0.05)$ during the first four months (Table 6). Thereafter, seedlings treated with the inoculum had a significantly higher root dry weights when compared to the non-treated seedlings until end of the nursery period. The dry weight of secondary roots of seedlings were not significantly different $(\mathrm{P}<0.05)$ between two treatments during the first three months (Table 7). After the third month, seedlings treated with the inoculum had significantly higher root dry weights than non-treated seedlings

Table 6: Effect of biofertilizer on primary root dry weight (g) of coconut seedlings

\begin{tabular}{lcccccccc}
\hline Treatments & \multicolumn{7}{c}{ Time (after treatment application) } \\
\hline & $1^{\text {st }}$ & $2^{\text {nd }}$ & $3^{\text {rd }}$ & $4^{\text {th }}$ & $5^{\text {th }}$ & $6^{\text {th }}$ & $7^{\text {th }}$ & $8^{\text {th }}$ \\
T1 & Month & Month & Month & Month & Month & Month & Month & Month \\
\cline { 2 - 9 } T2 & 2.14 & 3.51 & 6.90 & 9.37 & 13.77 & 16.90 & 19.99 & 27.97 \\
Significance & 2.55 & 2.92 & 5.61 & 6.86 & 9.77 & 10.86 & 12.17 & 16.75 \\
LSD & ns & ns & ns & ns & $*$ & $*$ & $*$ & $*$ \\
\hline
\end{tabular}

*Denote the significant difference at $p<0.05$; ns denote the non-significance

Table 7: Effect of biofertilizer on secondary root dry weight (g) of coconut seedlings

\begin{tabular}{lcccccccc}
\hline Treatments & \multicolumn{8}{c}{ Time (after treatment application) } \\
\hline & $1^{\text {st }}$ & $2^{\text {nd }}$ & $3^{\text {rd }}$ & $4^{\text {th }}$ & $5^{\text {th }}$ & $6^{\text {th }}$ & $7^{\text {th }}$ & $8^{\text {th }}$ \\
T1 & Month & Month & Month & Month & Month & Month & Month & Month \\
\cline { 2 - 9 } T2 & 0.18 & 0.59 & 3.52 & 4.20 & 6.92 & 10.42 & 13.23 & 24.26 \\
Significance & 0.15 & 0.36 & 1.40 & 2.66 & 5.06 & 6.52 & 8.27 & 16.06 \\
LSD & ns & ns & ns & ns & $*$ & $*$ & $*$ & $*$ \\
\hline
\end{tabular}

*Denote the significant difference at $p<0.05$; ns denote the non-significance

No tertiary roots were observed at the first sampling in both treatments but there were greater tertiary root dry weight in inoculated seedlings at the rest of the samplings when compared to the non-inoculated seedling. However, significantly higher tertiary root dry weights were observed in seedlings treated with the inoculum after four months of application when compared with noninoculated seedlings (Table 8).

Table 8: Effect of biofertilizer on tertiary root dry weight (g) of coconut seedlings

\begin{tabular}{lcccccccc}
\hline Treatments & \multicolumn{7}{c}{ Time (after treatment application) } \\
\hline & $1^{\text {st }}$ & $2^{\text {nd }}$ & $3^{\text {rd }}$ & $4^{\text {th }}$ & $5^{\text {th }}$ & $6^{\text {th }}$ & $7^{\text {th }}$ & $8^{\text {th }}$ \\
T1 & Month & Month & Month & Month & Month & Month & Month & Month \\
\cline { 2 - 8 } T2 & 0 & 0.02 & 0.70 & 1.35 & 1.73 & 3.29 & 4.81 & 5.53 \\
Significance & 0 & 0.00 & 0.08 & 0.18 & 1.05 & 1.56 & 2.14 & 2.63 \\
LSD & ns & ns & ns & $*$ & $*$ & $*$ & $*$ & $*$ \\
\hline
\end{tabular}

*Denote the significant difference at $p<0.05$; ns denote the non-significance 
Table 9: Effect of biofertilizer on quaternary root dry weight (g) of coconut seed

\begin{tabular}{lcccccccc}
\hline Treatments & \multicolumn{7}{c}{ Time (after treatment application) } \\
\hline & $1^{\text {st }}$ & $2^{\text {nd }}$ & $3^{\text {rd }}$ & $4^{\text {th }}$ & $5^{\text {th }}$ & $6^{\text {th }}$ & $7^{\text {th }}$ & $8^{\text {th }}$ \\
T1 & Month & Month & Month & Month & Month & Month & Month & Month \\
\cline { 2 - 9 } T2 & 0 & 0 & 0.16 & 0.43 & 2.67 & 5.45 & 5.84 & 6.41 \\
Significance & 0 & 0 & 0.01 & 0.60 & 1.08 & 2.63 & 2.75 & 3.16 \\
LSD & ns & ns & $*$ & $*$ & $*$ & $*$ & $*$ & $*$ \\
& - & - & 0.06 & 0.19 & 0.62 & 1.07 & 1.17 & 1.22 \\
\hline
\end{tabular}

*Denote the significant difference at $p<0.05$; ns denote the non-significance

Seedlings did not have any quaternary roots in the first and second months. However, it was three times higher in inoculated seedling when compared with the non-inoculated seedlings from the third month onwards. Significantly higher quaternary root dry weights were observed in inoculated seedlings compared to non-inoculated seedlings after the 5th month (Table 9). Total root dry weight was greater in the seedlings treated with inoculums when compared with the non-inoculated seedlings at all other samplings. From the fourth month, total root dry weights were significantly higher in inoculated seedlings (Table 10).

Table 10: Effect of biofertilizer on total root dry weight (g) of coconut seedlings

\begin{tabular}{lcccccccc}
\hline Treatments & \multicolumn{7}{c}{ Time (after treatment application) } \\
\hline & $1^{\text {st }}$ & $2^{\text {nd }}$ & $3^{\text {rd }}$ & $4^{\text {th }}$ & $5^{\text {th }}$ & $6^{\text {th }}$ & $7^{\text {th }}$ & $8^{\text {th }}$ \\
T1 & Month & Month & Month & Month & Month & Month & Month & Month \\
\cline { 2 - 9 } T2 & 2.32 & 4.12 & 11.29 & 15.37 & 25.11 & 36.08 & 43.89 & 64.18 \\
Significance & 2.71 & 3.29 & 7.12 & 9.77 & 11.97 & 25.58 & 25.34 & 38.61 \\
LSD & ns & ns & $*$ & $*$ & $*$ & $*$ & $*$ & $*$ \\
\hline
\end{tabular}

*Denote the significant difference at $p<0.05$; ns denote the non-significance

\section{Effect of treatments on shoot growth of coconut seedlings}

Leaf area of seedlings were not significantly different between two treatments $(P<0.05)$ during the first five months of nursery period (Table 11). The leaf area of bio-fertlizer treated seedlings was significant higher during 6th and 7th month of the nursery period. However, seedling treated with inoculums had higher leaf areas when compared to non-treated seedlings except in the first three months.

Table11: Effect of biofertilizer on leaf area $(\mathrm{cm} 2)$ of coconut seedling

\begin{tabular}{lccccccc}
\hline Treatments & \multicolumn{7}{c}{ Time (after treatment application) } \\
\hline & $1^{\text {st }}$ & $2^{\text {nd }}$ & $3^{\text {rd }}$ & $4^{\text {th }}$ & $5^{\text {th }}$ & $6^{\text {th }}$ & $7^{\text {th }}$ \\
T1 & Month & Month & Month & Month & Month & Month & Month \\
\cline { 2 - 8 } T2 & 210.21 & 571.8 & 795.8 & 1390.0 & 1477.3 & 2041.8 & 2060.9 \\
Significance & 224.99 & 659.2 & 845.6 & 1349.1 & 1340.8 & 1820.1 & 1394.9 \\
LSD & ns & ns & ns & ns & ns & $*$ & $*$ \\
\hline
\end{tabular}

*Denote the significant difference at $p<0.05$; ns denote the non-significance 
Seedlings grown with inoculums always showed marginally greater shoot dry weight when compared to seedlings grown without the inoculum in whole nursery period. Significantly higher shoot dry weights were observed at the end of the nursery period (6th and 7th months) in seedlings grown with inoculums compared to seedlings without inoculum (Table 12).

Table12: Effect of biofertilizer on shoot dry weight (g) of coconut seedling

\begin{tabular}{lccccccc}
\hline Treatments & \multicolumn{7}{c}{ Time (after treatment application) } \\
& $1^{\text {st }}$ & $2^{\text {nd }}$ & $3^{\text {rd }}$ & $4^{\text {th }}$ & $5^{\text {th }}$ & $6^{\text {th }}$ & $7^{\text {th }}$ \\
& Month & Month & Month & Month & Month & Month & Month \\
\cline { 2 - 8 } T1 & 12.87 & 23.51 & 28.89 & 47.90 & 66.99 & 88.23 & 105.60 \\
T2 & 15.87 & 28.13 & 28.07 & 60.71 & 59.29 & 67.13 & 87.73 \\
Significance & $\mathrm{ns}$ & $\mathrm{ns}$ & $\mathrm{ns}$ & $\mathrm{ns}$ & $\mathrm{ns}$ & $*$ & $*$ \\
LSD & - & - & - & - & - & 10.56 & 12.58 \\
\hline
\end{tabular}

*Denote the significant difference at $p<0.05$; ns denote the non-significance

There were no significant differences $(\mathrm{p}<0.05)$ in seedling heights between inoculated and non-inoculated seedlings (Table 13). However, seedlings grown with the inoculums had greater seedling heights when compared to seedlings grown without the inoculum during the whole nursery period.

Table13: Effect of biofertilizer on coconut seedling height $(\mathrm{cm})$

\begin{tabular}{lccccccc}
\hline Treatments & \multicolumn{7}{c}{ Time (after treatment application) } \\
\hline & $1^{\text {st }}$ & $2^{\text {nd }}$ & $3^{\text {rd }}$ & $4^{\text {th }}$ & $5^{\text {th }}$ & $6^{\text {th }}$ & $7^{\text {th }}$ \\
T1 & Month & Month & Month & Month & Month & Month & Month \\
\cline { 2 - 8 } T2 & 51.32 & 48.48 & 69.67 & 76.80 & 89.37 & 100.60 & 98.00 \\
Significance & 44.57 & 46.50 & 70.55 & 83.15 & 89.12 & 99.75 & 100.50 \\
LSD & ns & ns & ns & ns & ns & ns & ns \\
\hline
\end{tabular}

*Denote the significant difference at $p<0.05$; ns denote the non-significance

There were no significant differences in seedling girth between treatments during first five months of the nursery period. However, significantly higher seedling girths were observed at the latter stage of the nursery period ( $6^{\text {th }}, 7^{\text {th }}$ months) in seedlings grown with biofertilizer (Table 14$)$.

Table 14: Effect of biofertilizer on coconut seedling girth $(\mathrm{cm})$

\begin{tabular}{lccccccc}
\hline Treatments & \multicolumn{7}{c}{ Time (after treatment application) } \\
\hline & $1^{\text {st }}$ & $2^{\text {nd }}$ & $3^{\text {rd }}$ & $4^{\text {th }}$ & $5^{\text {th }}$ & $6^{\text {th }}$ & $7^{\text {th }}$ \\
& Month & Month & Month & Month & Month & Month & Month \\
\cline { 2 - 8 } T1 & 9.30 & 10.90 & 10.75 & 13.25 & 13.10 & 15.25 & 15.00 \\
T2 & 9.80 & 10.82 & 11.07 & 14.60 & 13.87 & 13.70 & 14.12 \\
Significance & ns & ns & ns & ns & ns & $*$ & $*$ \\
LSD & - & - & - & - & - & 1.45 & 0.30 \\
\hline
\end{tabular}

*Denote the significant difference at $p<0.05$; ns denote the non-significance 


\section{DISCUSSION}

This study was intended to assess the impact of an AMF based biofertilizer on the root and shoot development of the coconut seedlings at nursery stage. The highest growth rate was observed for biofertilizer treated coconut seedlings implying that biofertilizer has a more positive effect on the growth of coconut seedlings. Auge (2001) reported that plants treated with AMF inoculation have deeper and more extensive root systems. Moreover, Berta et al., (1993) and Espeleta et al., (1999) reported that AM colonization can change specific root length, root architecture and root/shoot ratio of Prunus cerasifera as observed in this study.

Thus, AMF inoculation significantly increases the shoot growth of coconut seedlings. Similar results were found in the case of corn (Kothari et al., 1990), lettuce (Tobar et al., 1994b) and maize (Subaramanian et al., 1995). A positive response of shoot growth to AMF inoculation has been all so reported in sorghum (Ebel et al., 1994) and wheat (Panwar, 1993). It is widely reported AM fungi can enhanced the host plant growth and development whilst improving nutrient status of the host plant. Researchers show AM fungi can assist most of the plants by increasing the growth, development and nutrient status of the host plants (Chen et al., 2008; Sun et al., 2008; Zhang et al., 2011). Experiment results showed that AM fungi can increase plant shoot and root growth. Seedling girth, leaf area and shoot dry weight of the coconut seedlings showed significant differences at the latter part of the nursery period. These results conferm to those of $\mathrm{Wu}$ (2011) who observed that the enhanced efficacy of mycorrhizas was more obvious for root than for shoot or total dry weight of Peach (Prunus persica L. batsch) seedlings. In addition, these results agree with those of with the findings of Yao et al., (2005) in Litchi (Litchi chinensis) and Wu et al., (2007) in red tangerine (Citrus tangerine).

The results also state that AMF symbiosis influences significantly rooting area. Thus, root volume of inoculated coconut seedlings was multiplied two times according to the noninoculated seedlings. The importance of the root system was due to the presence of a large number of rootlets, supporting the notion that AM fungi can increase the rooting zone. This experiment data also suggest that the positive effects on root volume could be correlated to improvement of coconut seedling growth. Indeed, like certain filamentous fungi species, AM fungi secretes in the rhizosphere some phosphatases (Tarafdar and Marschner, 1994) and organic acids such as the oxalic acid, catalyzing the hydrolysis of the connections phosphoesters (Plenchette, 2005) and thus placing phosphorus at the disposal of the plants. The higher root growth of primary, secondary, tertiary and quaternary by biofertilizer treatments improves the efficient water uptake and nutrient absorption and it leads to develop a good quality coconut seedling. However, the increase in shoot development is also a beneficial character for a seedling because it increases photosynthesis rates and dry matter production which is helpful for root and shoot growth of the plant. However, having a balanced shoot/ root ratio is important for a seedling to obtain a better partitioning of dry matter.

\section{CONCLUSION}

The present study illustrated that the application of an AMF based bio fertilizer (MYCOgold) had no significant effect on selected root growth parameters in the early stages (up to third month). However, it increased the volumes and dry weights of primary, secondary, tertiary 
and quaternary roots and stem girth at the latter stages of coconut seedling growth. The leaf area and seedling height were not significantly increased by the AMF based bio fertilizer during the nursery period. These results revealed that the usage of AMF based bio fertilizer positively affected root development and stem girth of coconut seedlings. The application of the AMF based bio fertilizer seems to be beneficial to produce quality seedlings with well-developed roots and thus obtain good field establishment, thereby reducing the number casualties during field establishment.

\section{REFERENCES}

Auge, R. M. (2001). Water relations, drought and vesicular-arbuscular mycorrhizal symbiosis. Mycorrhiza, 11: 3-42.

Barea, J.M., El-Atrach and Azcon, R. (1991). The role of VA Mycorrhizas ub improving plant $\mathrm{N}$ acquisitions from soil as assessed with $15 \mathrm{~N}$. In: Fitton, C. (ed). The use of stable isotopes in Plant Nutrients, Soil Fertility and Environmental Studies, pp: 677-808.

Betra, G., Fusconi, A. and Trotta, A. (1993). VA mycorrhizal infection and the morphology and function of root systems. Journal of Environmental Botany 33: 159-173.

Burdette, A.M. (1979). A non-destructive method for measuring the volume of intact plant parts. Canadian Journal of Forest Research, 9: 120-122.

Castellano, M.A.; Molina, R. (1989). Mycorrhizae. In: Landis, T.D.; Tinus, R.W.; McDonald, S.E.; Barnett, J.P. The Container Tree Nursery Manual, Volume 5. Agric. Handbook. 674. Washington, DC: U.S. Department of Agriculture, Forest Service: 101-167.

Central Bank of Sri Lanka, (2012). Annual Report, Central Bank of Sri Lanka, Janadhipathi Mawatha, Colombo 01. 41-42.

Clark, R.B. and Zeto, S.K. (2000). Mineral acquisition by arbuscular mycirrhizal plants. Journal of Plant Nutrients, 23: 867-902.

Coyne, J. and Mark, H. (1999). Soil Microbiology: An Exploratory Approach. Delmar Publishers. Albany, New York, ppg 6-7.

Chen, Z. C., Shi, S. Y., Tian, C.Y. (2008). Effects ofarbuscular mycorrhizal fungal inoculation on growth and nutrient uptake of two ephemeral plants. Chines Journal of Plant Ecology, 32: 648-653.

Ebel, R.C., Stodola, A.J.W., Duan, X., Auge, R.M. (1994). Nonhydraulic root to shoot signaling in mycorrhizal sorghum exposed to partial soil drying or root severing. New Phytology, 127:495-506.

Espeleta J. F., Eissenstat, D. M. and Graham, J. H. (1999). Citrus root responses to localized drying soil: a new approach to studying mycorrhizal effects on the roots of mature trees. Plant and Soil 206: 1-10. 
Gianinazzi, S., Schuepp, H., Barea, J.M., and Haselwandter, K. (2002). Mycorrhizal Technology in Agriculture: From Genes to Bioproducts. Birkhäuser, Basel, pp. 296.

Javaid, A. (2007). Allelopathic interactions in mycorrhizal associations. Allelopathy Journal, 20:29-42.

Jeffries, P., Barea, J.M., (2000). Arbuscular mycorrhiza key component of sustainable plant-soil ecosystems. In: Hock, B. (Ed.), The Mycota, Volume IX. Fungal Associations. SpringerVerlag, pp. 95-113.

Khaosaad, T., Garcia-Garrido, J.M., Steinkellner, S. and Vierheilig, H. (2007). Take all diseases is systemically reduced in roots of mycodrrhizal barley plants. Soil Biology and Biochemistry, 39: 727-734.

Kothari, S.K., Marschner, H., George, E. (1990). Effect of VA mycirrhizal fungi and rhizosphere microorganisms on root and shoot morphology, growth and water relations in maize, New Phytology, 116:303-311.

Linderman, R.G. and Davis, E.A. (2004). Evaluation of Commercial Inorganic and Organic Fertilizer Effects on Arbuscular Mycorrhizae Formed by Glomus intraradices. Horticulture Technology 14 (2) 196-202.

Marx, D.H., Cordeia, C.E., Manul, S. B. and Ruehle, J.L. (1989). Ectomycorrhizal development on pine by Pisolithus tinctorius in bare-root and container seeding nurseries. 1. Efficiency of various vegetative inoculums formulations. New Forests 3: 45-56.

Menon, K.P.V. and Pandalai, K.M. (1958). The coconut palm; A Monograph, Indian Central Coconut Committee, South India.

Miller, R.M. and Jastrow, J.D. (1992). The applicatio1991n of VA mycorrhizae to ecosystem restoration and reclamation. In: Allen, M.F. (Ed.), Mycorrhizal Functioning. Chapman \& Hall, Ltd., London, England, pp. 438-467.

Panwar, J.D.S. (1993). Effect of VAM and Azospirillum on growth and yield of wheat. Indian Journal of Plant Physiology, 34: 357-361.

Plenchette, C. (2005). Mycorhizes et nutritions phosphate des plantes. Journess techniques fruits and legumes, Vitculutute Bioligiques, 103-109.

Senarathne, S.H.S, J.K.D.S.W.Jayaneththi and K.P.P.Premarathne (2012). The effect of different concentration of glyphosate on the grwoth of coconut seedlings, Korean Journal of Weed Science, 32 (3): 230-239.

Subaramanian, K.S., Charest, C., Dwyer, L.M., Hamilton, R.I. (1995). Arbuscular mycorrhizas and water relations in maize under drought stress at tasseling, New Phytology, 129: 643650.

Sun, Y., Li, X. L., Feng, G. (2008). Effect of arbuscular mycirrhizal fungi colonization on ecological functional traits of ephemerals in Gurbantonggut desert. Symbiosis, 46: 121-127. 
Tarafdar, J.C., Marschner, H. (1994). Efficiency of VAM hyphae in utilization of organic phosphorus by wheat plants. Soil science, Plant Nutrition, 40: 593-600.

Tobar, R., Azcon, R., Barea, J.M. (1994b). The improvement of plant N acquisition from an ammonium treated, drought stressed soil by the fungal symbiotic in Arbuscular mycorrhizae, 4: 105-108.

Ward, N.I., Stead, K. and Reeves, J. (2001). Impact of ebdimycirrhizal fungi on plant trace elements uptake and nutrient. Nutrient Practice, 32: 30-31.

Wu, Q. S., Zou, Y. N. , Xia, R. X. and Wang, M. Y. (2007). Five Glomus species affect water relations of Citrus tangerine during drought stress. Experimental Botany, 48:147-154.

Wu, Q.S., Li, G.H. and Zou, Y. N. (2011). Roles of arbuscular mycorrhizal fungion growth and nutrient acquisition peach (Prunus persica L. BATSCH) seedlings, The Journal of Animal \& Plant Sciences, 21(4): 746-750.

Yao, Q., Zhu, H. H. and Chen, J. Z. (2005). Growth responses and endogenous IAA and iPAs changes of litchi (Litchi chinensis Sonn.) seedlings induced by arbuscular mycorrhizal fungal inoculation. Horticulture Science 105:145-151.

Zhang, T., Sum, Y., Song, Y.C. (2011). On site growth response of a desert ephemeral plant, Plantago minuta, to indigenous arbuscular mycorrhizal fungi in a central Asia desert. Symbiosis, 55: 77-84. 